\title{
Association between polymorphism within interleukin related genes and Graves' disease: a meta-analysis of 22 case-control studies
}

\author{
Yaqin Tu ${ }^{1, *}$, Guorun Fan ${ }^{1, *}$, Tianshu Zeng ${ }^{2}$, Xiong Cai ${ }^{3}$ and Wen Kong ${ }^{2}$ \\ ${ }^{1}$ Department of Otorhinolaryngology, Union Hospital, Tongji Medical College, Huazhong University of Science and Technology, \\ Wuhan 430022, China \\ ${ }^{2}$ Department of Endocrinology, Union Hospital, Tongji Medical College, Huazhong University of Science and Technology, \\ Wuhan 430022, China \\ ${ }^{3}$ Department of Hepatobiliary Surgery, Union Hospital, Tongji Medical College, Huazhong University of Science and Technology, \\ Wuhan 430022, China \\ "These authors contributed equally to this work
}

Correspondence to: Wen Kong, email: wenly-kong@163.com

Xiong Cai, email: caixiong@live.com

Keywords: Graves' disease, interleukin, polymorphism, susceptibility, case/control study

Received: May 24, $2017 \quad$ Accepted: July 25, $2017 \quad$ Published: August 10, 2017

Copyright: Tu et al. This is an open-access article distributed under the terms of the Creative Commons Attribution License 3.0 (CC BY 3.0), which permits unrestricted use, distribution, and reproduction in any medium, provided the original author and source are credited.

\section{ABSTRACT}

Graves' disease (GD) is a common autoimmune disorder with a genetic predisposition. There is strong evidence to suggest that both Th1 and Th 2 circulating cytokines are involved in the development of GD. In this study, we conducted a meta-analysis to assess the impact of seven variations of five $I L$-related genes on the susceptibility to GD. A total of 22 case-control studies involving 5338 GD patients and 6446 healthy controls were included. The results showed that only one SNP rs1800795 in IL-6 was significantly associated with GD in homozygous model (CC vs. GG: OR $=2.714,95 \% \mathrm{CI}=1.047-7.039, p=0.04$ ), heterozygous model (CG vs. GG: $O R=1.295,95 \% C I=1.013-1.655, p=0.039)$, dominant model $(C C+C G$ vs. GG: $O R=1.418,95 \% C I=1.122-1.793, p=0.003$ ) and additive model (C vs. G: $O R=1.432,95 \% C I=1.087-1.886, p=0.011)$. To explain the heterogeneity, we performed the subgroup analysis by ethnicity. The ethnicity stratification revealed that the association between rs1800795 and GD tended to be much stronger for Asian than European population in homozygous, dominant, recessive, and additive models. The remaining 6 SNPs in 4 genes did not show any significant association with GD in any genetic models. Together, our data support that rs1800795 within the IL-6 gene confers genetic susceptibility for GD. Future large-scale studies are required to validate the associations between $I L-6$ and others $I L$-related genes and GD.

\section{INTRODUCTION}

Graves' disease (GD) is an autoimmune thyroid disease with a prevalence of $0.5 \%$ in the general population [1-2]. GD is characterized by the presence of thyroid-stimulating hormone (TSH) receptor antibodies, which leads to hyperthyroidism and goiter. The exact etiology of GD remains unknown; however, it is believed that genetic polymorphisms and environmental factors are both involved in the pathogenesis of GD. Large familial clustering and twin studies have proposed that about $79 \%$ of the risk for developing GD may be related to genetic factors, whereas $21 \%$ of them were related to the environmental and endogenous factors [3-4]. Genome-wide association studies (GWASs) have reported loci for GD on chromosomal region 5q31-q33 in Asian populations [5]. This region includes the $\mathrm{T}$ helper 1 (Th1) and Th2 gene cluster, which encodes certain cytokines, including the inflammation-associated proteins interleukin (IL)-4, IL-12, and IL-13. In addition, another 
GWAS revealed that IL-6 and IL-10 are related to the pathogenesis of GD [6-8].

IL-4, IL-6, IL-10, and IL-12 are produced by intrathyroidal inflammatory cells and thyroid follicular cells. IL-13 is an important immunoregulatory cytokine involved in the IgE synthesis and is associated with Th2-mediated disease. The serum levels of IgE and IL-13 may be the indicators of remission or recurrence of GD [9-10]. Genetic factors that affect the induction or inhibition of these cytokines are the potential candidates for GD sensitivity. Indeed, emerging studies had shown that over 70 variations in 22 IL-related genes $(I L-1 B, I L-1 \alpha, I L-1 \beta$, $I L-2, I L-3, I L-4, I L-5, I L-6, I L-8, I L-9, I L-10, I L-12, I L-$ $12 A, I L-13, I L-16, I L-17, I L-17 F, I L-18, I L-18 R, I L-21$, $I L-23$, and $I L-33)$ are associated with GD. Nevertheless, the results are conflicting due to the limited sample size of each study. We, therefore, in the current report, conducted a meta-analysis of seven single nucleotide polymorphisms (SNPs) in five cytokine genes from all eligible case-control studies that included more than three studies to assess the associations among reported IL-related genes with GD.

\section{RESULTS}

\section{Workflow for the identification of eligible datasets}

A total of 116 publications were characterized based on our keyword search. After screening the titles and abstracts, 67 studies were identified as irrelevant, and eight articles were characterized as reviews. Additionally, 17 studies were excluded because 10 of the articles focused on different genes. Another seven articles were excluded because they were not on GD research (two studies), were not case control studies (three studies), or did not assess polymorphisms (two articles). Among the remaining 24 publications, two studies were also rejected as they either failed to provide detailed genotyping information (one article) or were published in non-English journals (one study) (Figure 1).

\section{Characteristics of the selected datasets}

A total of 22 case control datasets were identified based on our inclusion criteria. Of these, 22 studies, including 5338 patients with GD and 6446 healthy controls, were analyzed. The principal characteristics and genotype distributions of the identified studies are shown in Table 1. Among the included articles, 16 studies were from Asian populations [6-7, 9, 11-23] and 6 studies were from European populations [24-29]. Genotypic distribution for all SNPs in controls was in consistent with HWE $(p>0.05)$ except for the 3 datasets highlighted in bold (Table 1). The quality of each study was assessed through Newcastle-Ottawa assessment scale (NOS), as shown in Table 2. All included studies scored 7 or 8 , indicating sufficient quality for their inclusion in the metaanalysis.
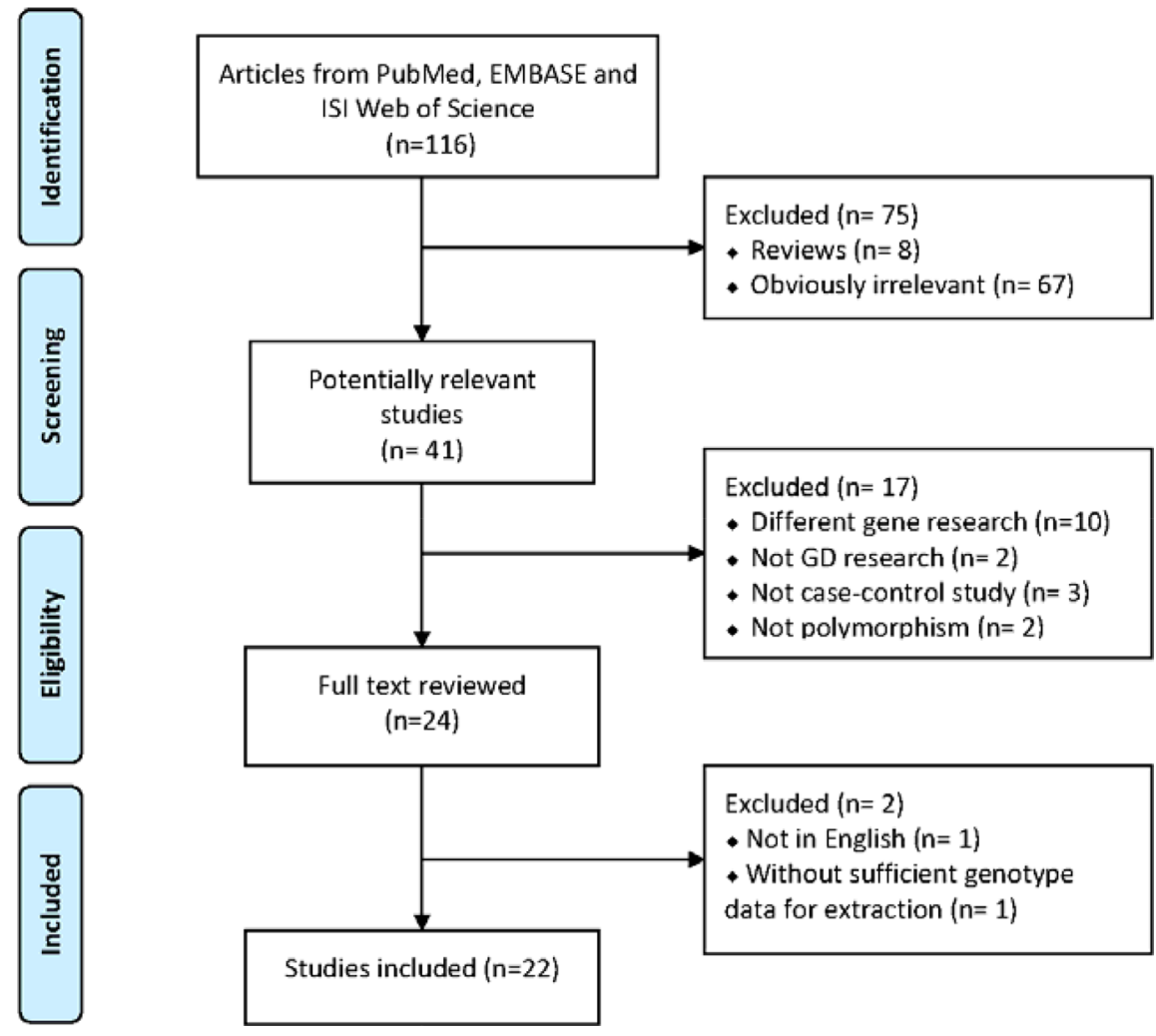

Figure 1: PRISMA flow diagram showing the search strategy. 
Table 1: Characteristic of datasets included for meta-analysis

\begin{tabular}{|c|c|c|c|c|c|c|c|c|c|c|c|c|c|c|c|}
\hline \multirow{2}{*}{ ID } & \multirow{2}{*}{ Author } & \multirow{2}{*}{ Year } & \multirow{2}{*}{ Ethnicity } & \multirow{2}{*}{$\begin{array}{l}\text { Genotyping } \\
\text { method }\end{array}$} & \multirow{2}{*}{$\begin{array}{l}\text { Study } \\
\text { design }\end{array}$} & \multirow{2}{*}{ Gene } & \multirow{2}{*}{$\begin{array}{c}\text { Case/ } \\
\text { Control }\end{array}$} & \multirow{2}{*}{ SNP loci } & \multicolumn{3}{|c|}{ GD } & \multicolumn{3}{|c|}{ Control } & \multirow{2}{*}{$p H W E$} \\
\hline & & & & & & & & & 11 & 12 & 22 & 11 & 12 & 22 & \\
\hline 1 & Jung-Pil Jang & 2016 & Asian & hybridization & $\mathrm{CC}$ & IL-13 & $60 / 192$ & rs1800925 & 36 & 24 & 0 & 129 & 61 & 2 & 0.07 \\
\hline 2 & Duraes & 2014 & European & Taqman & $\mathrm{CC}$ & IL-6 & $111 / 735$ & rs1800795 & 13 & 61 & 37 & 92 & 324 & 319 & 0.5 \\
\hline 3 & Faruk Kutluturk & 2013 & European & PCR-SSP & $\mathrm{CC}$ & IL-6 & $100 / 124$ & rs1800795 & 12 & 36 & 52 & 6 & 41 & 77 & 0.86 \\
\hline 4 & Yann-Jinn Lee & 2011 & Asian & Taqman & $\mathrm{CC}$ & IL-4 & $220 / 904$ & rs 2243250 & 9 & 64 & 147 & 38 & 255 & 611 & 0.087 \\
\hline 5 & N. Inoue & 2011 & Asian & PCR-RFLP & $\mathrm{CC}$ & IL-13 & $78 / 68$ & rs1800925 & 60 & 16 & 2 & 53 & 14 & 1 & 0.95 \\
\hline 6 & Nan Liu & 2011 & Asian & $\begin{array}{l}\text { GenomeLab } \\
\text { SNPstream }\end{array}$ & $\mathrm{CC}$ & IL-10 & $725 / 696$ & rs 1800872 & 321 & 326 & 78 & 299 & 310 & 87 & 0.63 \\
\hline \multirow{2}{*}{7} & \multirow{2}{*}{$\begin{array}{l}\text { Omid } \\
\text { Khalilzadeh }\end{array}$} & \multirow{2}{*}{2010} & \multirow{2}{*}{ Asian } & \multirow{2}{*}{ PCR-SSP } & \multirow{2}{*}{$\mathrm{CC}$} & \multirow{2}{*}{ IL-4 } & $107 / 139$ & rs 2243250 & 50 & 52 & 5 & 10 & 129 & 0 & 0.00 \\
\hline & & & & & & & $107 / 139$ & rs2070874 & 29 & 50 & 28 & 61 & 78 & 0 & 0.00 \\
\hline 8 & W, Zhu & 2010 & Asian & $\begin{array}{l}\text { GenomeLab } \\
\text { SNPstream }\end{array}$ & $\mathrm{CC}$ & IL-4 & $731 / 716$ & rs2070874 & 453 & 253 & 25 & 461 & 231 & 24 & 0.45 \\
\hline \multirow{2}{*}{9} & \multirow{2}{*}{ Mehdi Anvari } & \multirow{2}{*}{2010} & \multirow{2}{*}{ Asian } & \multirow{2}{*}{ PCR-SSP } & \multirow{2}{*}{$\mathrm{CC}$} & IL-6 & $107 / 139$ & rs1800795 & 27 & 63 & 17 & 4 & 93 & 42 & 0.00 \\
\hline & & & & & & IL-12 & $107 / 140$ & rs3212227 & 34 & 53 & 20 & 72 & 60 & 8 & 0.32 \\
\hline \multirow{2}{*}{10} & Kelvin K. L. & 2008 & Asian & PCR-RFLP & $\mathrm{CC}$ & II -13 & $177 / 151$ & rs1800925 & 120 & 51 & 6 & 106 & 44 & 1 & 0.11 \\
\hline & Chong & & Aslant & РСК-КГLР & $C$ & $1 L-13$ & $1 / 7 / 151$ & rs20541 & 68 & 81 & 28 & 66 & 67 & 18 & 0.87 \\
\hline 11 & Nanba & 2008 & Asian & Sequencing & $\mathrm{CC}$ & IL-4 & $50 / 26$ & rs 2243250 & 4 & 22 & 24 & 2 & 11 & 13 & 0.88 \\
\hline 12 & $\begin{array}{l}\text { Rong-Hsing } \\
\text { Chen }\end{array}$ & 2007 & Asian & $\begin{array}{l}\text { GenomeLab } \\
\text { SNPstream }\end{array}$ & $\mathrm{CC}$ & IL-4 & $104 / 105$ & rs 2243250 & 4 & 32 & 68 & 2 & 36 & 67 & 0.25 \\
\hline & & & & & & IL-10 & $133 / 134$ & rs1800872 & 62 & 54 & 17 & 72 & 52 & 10 & 0.89 \\
\hline 13 & $\begin{array}{l}\text { Ming-Yuh } \\
\text { Shiau }\end{array}$ & 2007 & Asian & PCR-RFLP & $\mathrm{CC}$ & 4 & $130 / 101$ & rs2070874 & 93 & 34 & 3 & 68 & 31 & 2 & 0.47 \\
\hline & & & & & & & $137 / 119$ & rs 2243250 & 6 & 48 & 83 & 6 & 35 & 78 & 0.43 \\
\hline 14 & Yuji Hiromatsu & 2006 & Asian & Sequencing & $\mathrm{CC}$ & IL-12 & $329 / 226$ & rs 3212227 & 77 & 162 & 90 & 39 & 120 & 67 & 0.24 \\
\hline 15 & Yang & 2005 & Asian & Sequencing & $\mathrm{CC}$ & IL-4 & $187 / 131$ & rs 2243250 & 7 & 51 & 129 & 2 & 46 & 83 & 0.12 \\
\hline 16 & Yukio Ikeda & 2004 & Asian & PCR-RFLP & $\mathrm{CC}$ & IL-12 & $90 / 123$ & rs3212227 & 22 & 39 & 29 & 29 & 64 & 30 & 0.65 \\
\hline 17 & Yuii Hiromatsu & 2004 & Asian & PCR_RFI P & CC & JI-13 & $310 / 244$ & rs1800925 & 219 & 83 & 8 & 143 & 88 & 13 & 0.91 \\
\hline & & & & & & & & rs 20541 & 166 & 123 & 21 & 113 & 100 & 31 & 0.24 \\
\hline 18 & Bednarczuk, T & 2004 & Asian & PCR-RFLP & $\mathrm{CC}$ & IL-6 & $279 / 186$ & rs1800795 & 56 & 138 & 85 & 27 & 101 & 58 & 0.11 \\
\hline 19 & Karen F, Tait & 2004 & European & Invader assay & $\mathrm{CC}$ & IL-10 & $630 / 846$ & rs1800872 & 32 & 234 & 364 & 35 & 290 & 521 & 0.50 \\
\hline 20 & Tomasz & 2003 & Furonean & SSCP & CC & J -13 & $261 / 168$ & rs1800925 & 127 & 108 & 26 & 89 & 63 & 16 & 0.33 \\
\hline & Bednarczuk & 2003 & European & & & & & rs20541 & 148 & 94 & 19 & 94 & 66 & 8 & 0.40 \\
\hline 21 & Heward & 2001 & European & PCR-RFLP & $\mathrm{CC}$ & IL-4 & $381 / 285$ & rs 2243250 & 277 & 99 & 5 & 222 & 58 & 5 & 0.59 \\
\hline 22 & Hunt & 2000 & European & PCR-SSP & $\mathrm{CC}$ & IL-4 & $138 / 101$ & rs 2243250 & 122 & 15 & 1 & 75 & 23 & 3 & 0.46 \\
\hline
\end{tabular}

11: wild-type homozygote, 12: heterozygote, 22: variant homozygote.

CC: case/control.

HWE: Hardy-Weinberg equilibrium.

PCR-SSCP: PCR-single-strand conformation polymorphism.

PCR-SSP: PCR-sequence specific primer.

\section{Association between IL-related gene polymorphism and Graves' disease}

We performed a meta-analysis of seven SNPs in five $I L$-related genes, including $I L-4$ (rs2243250 and rs2070874), $I L-6$ (rs1800795), $I L-10$ (rs1800872), IL-12 (rs3212227), and $I L-13$ (rs1800925 and rs20541).The number of the included datasets on each SNP ranged from 3 to 8 . Unexpectedly, only one SNP (rs1800795) in $I L-6$ was found to have a significant association with GD in the homozygous model (CC vs. GG: $\mathrm{OR}=2.714,95 \% \mathrm{CI}=$ $1.047-7.039, p=0.04)$, heterozygous model (CG vs. GG: $\mathrm{OR}=1.295,95 \% \mathrm{CI}=1.013-1.655, p=0.039)$, dominant model $(\mathrm{CC}+\mathrm{CG}$ vs. $\mathrm{GG}$ : $\mathrm{OR}=1.418,95 \% \mathrm{CI}=1.122$ -
1.793, $p=0.003)$ and additive model $(\mathrm{C}$ vs. $\mathrm{G}: \mathrm{OR}=1.432$, $95 \% \mathrm{CI}=1.087-1.886, p=0.011)($ Table 2; Figure 2). Our meta-analysis of rs 1800795 was hampered by high heterogeneity. A random effect model was thus used. To explain the heterogeneity, we performed the subgroup analysis by ethnicity. The ethnicity stratification revealed that the association between rs 1800795 and GD tended to be much stronger for Asian populations than for European populations in the homozygous, dominant, recessive, and additive models (Supplementary Figure 1).

The remaining 6 SNPs in the 4 genes did not show significant association with GD in any genetic model (Table 3). Among the insignificant polymorphisms, rs2243250 in $I L-4\left(\mathrm{I}^{2}<85.2 \%\right)$, rs2070874 in $I L-4\left(\mathrm{I}^{2}<\right.$ 
Table 2: Quality assessments of case-control studies according to the Newcastle Ottawa Scale

\begin{tabular}{|c|c|c|c|c|c|c|c|c|c|c|c|c|}
\hline \multirow{2}{*}{$\begin{array}{c}\text { Study } \\
\text { ID }\end{array}$} & \multirow{2}{*}{ Author } & \multirow{2}{*}{ Year } & \multicolumn{4}{|c|}{ Selection } & \multicolumn{2}{|c|}{ Comparability } & \multicolumn{3}{|c|}{ Exposure } & \multirow{2}{*}{ Total score } \\
\hline & & & $\mathbf{a}$ & b & c & d & e & f & g & h & $\mathbf{i}$ & \\
\hline 1 & Jung-Pil Jang & 2016 & $*$ & $*$ & 1 & l & $*$ & $*$ & $*$ & $*$ & $*$ & 7 \\
\hline 2 & Duraes & 2014 & $*$ & $*$ & / & * & $*$ & $*$ & $*$ & $*$ & $*$ & 8 \\
\hline 3 & Faruk Kutluturk & 2013 & $*$ & $*$ & l & * & $*$ & $*$ & $*$ & $*$ & $*$ & 8 \\
\hline 4 & Yann-Jinn Lee & 2011 & $*$ & $*$ & 1 & * & $*$ & $*$ & $*$ & $*$ & $*$ & 8 \\
\hline 5 & N. Inoue & 2011 & $*$ & $*$ & / & / & $*$ & $*$ & $*$ & $*$ & $*$ & 7 \\
\hline 6 & Nan Liu & 2011 & $*$ & $*$ & / & * & $*$ & $*$ & $*$ & $*$ & $*$ & 8 \\
\hline 7 & Omid Khalilzadeh & 2010 & $*$ & $*$ & l & $*$ & $*$ & / & $*$ & $*$ & $*$ & 7 \\
\hline 8 & W, Zhu & 2010 & $*$ & $*$ & / & $*$ & $*$ & $*$ & $*$ & $*$ & $*$ & 8 \\
\hline 9 & Mehdi Anvari & 2010 & $*$ & $*$ & / & $*$ & $*$ & l & $*$ & $*$ & $*$ & 7 \\
\hline 10 & Kelvin K. L. Chong & 2008 & $*$ & $*$ & / & $*$ & $*$ & $*$ & $*$ & $*$ & $*$ & 8 \\
\hline 11 & Nanba & 2008 & $*$ & $*$ & / & / & $*$ & $*$ & $*$ & $*$ & $*$ & 7 \\
\hline 12 & Rong-Hsing Chen & 2007 & $*$ & $*$ & / & * & $*$ & $*$ & $*$ & $*$ & $*$ & 8 \\
\hline 13 & Ming-Yuh Shiau & 2007 & $*$ & $*$ & l & / & $*$ & $*$ & $*$ & $*$ & $*$ & 7 \\
\hline 14 & Yuji Hiromatsu & 2006 & $*$ & $*$ & / & * & $*$ & $*$ & $*$ & $*$ & $*$ & 8 \\
\hline 15 & Yang & 2005 & $*$ & $*$ & l & * & $*$ & l & $*$ & $*$ & $*$ & \\
\hline 16 & Yukio Ikeda & 2004 & $*$ & $*$ & / & $*$ & $*$ & $*$ & $*$ & $*$ & $*$ & 8 \\
\hline 17 & Yuji Hiromatsu & 2004 & $*$ & $*$ & / & $*$ & $*$ & $*$ & $*$ & $*$ & $*$ & 8 \\
\hline 18 & Bednarczuk, T & 2004 & $*$ & $*$ & l & / & $*$ & $*$ & $*$ & $*$ & $*$ & 7 \\
\hline 19 & Karen F, Tait & 2004 & $*$ & $*$ & / & $*$ & $*$ & l & $*$ & $*$ & $*$ & 7 \\
\hline 20 & Tomasz Bednarczuk & 2003 & $*$ & $*$ & I & l & $*$ & $*$ & $*$ & $*$ & $*$ & 7 \\
\hline 21 & Heward & 2001 & $*$ & $*$ & / & $*$ & $*$ & l & $*$ & $*$ & $*$ & 7 \\
\hline 22 & Hunt & 2000 & $*$ & $*$ & / & $*$ & $*$ & I & $*$ & $*$ & $*$ & 7 \\
\hline
\end{tabular}

Publication quality check list:

a: Is the case definition adequate?;

b: Representativeness of the cases;

c: Selection of Controls;

d: Definition of Controls;

e: study controls for ethnicity;

f: study controls for any additional factor;

$\mathrm{g}$ : Ascertainment of exposure;

$\mathrm{h}$ : Same method of ascertainment for cases and controls;

i: Non-Response rate.

$88.8 \%)$, rs 1800872 in $I L-10\left(\mathrm{I}^{2}<53.3 \%\right)$, rs3212227 in $I L-12\left(\mathrm{I}^{2}<87.0 \%\right)$, rs1800925 in $I L-13\left(\mathrm{I}^{2}<63.9 \%\right)$, and rs20541 in $I L-13\left(\mathrm{I}^{2}<75.9 \%\right)$ were hampered by high heterogeneity. Considering the limited number of studies, we only performed subgroup analysis of variations with more than 3 articles (rs2243250 in $I L-4$ and rs 1800925 in $I L-13)$. Ethnicity stratification showed that these two SNPs did not show significant associations with GD in Asian and European populations (Supplementary Table 1).

\section{Publication bias}

Begg's funnel plot and Egger's test were performed to assess the publication bias. The shape of the funnel plots appeared to be symmetrical (SNP rs1800795 in $I L-6)$ and the Egger's test did not show any evidence of publication bias (Figure 3). The sensitivity analyses also indicated that results of our study were stable and reliable (data not shown).

\section{DISCUSSION}

In the present study, we examined the association between variations in IL-related genes and GD. The results of our overall meta-analysis supported that only G->C mutation at rs1800795 in IL-6 was a risk factor for GD. The other 6 variations in the 4 genes (IL- 4 rs 2243250 , IL-4 rs2070874, IL-10 rs1800872, IL-12 rs3212227, IL-13 rs1800925 and IL-13 rs20541) did not show a significant association with GD in any genetic model. Considering the fact that the ethnic background may affect the results of genetic association studies, we performed a subgroup 
analysis by ethnicity and found that the association was more apparent among Asian populations, indicating that IL-6 polymorphism may exert varying effects in different populations. This is perhaps because different populations are exposed to diverse environments during their evolution and different life styles. These results were consistent with the findings of Mehdi Anvari et al in an Iranian population [14]. IL-6 plays an important role in the growth and differentiation of lymphocytes, which might contribute to the promotion of thyroid receptor antibody synthesis during the course of GD. IL-6 rs1800795, which is located in the $5^{\prime}$ promoter region at position $-174(\mathrm{G}-174 \mathrm{C})$, appears to influence IL-6 production. Moreover, there are evidences indicating that the $\mathrm{C}$ allele results in lower transcriptional activity than the G allele [30-31]. In line with this notion, subjects carrying the putative risk $\mathrm{C} / \mathrm{C}$ genotype show lower plasma IL-6 levels than subjects carrying the $\mathrm{G} / \mathrm{G}$ genotype. These findings suggest that

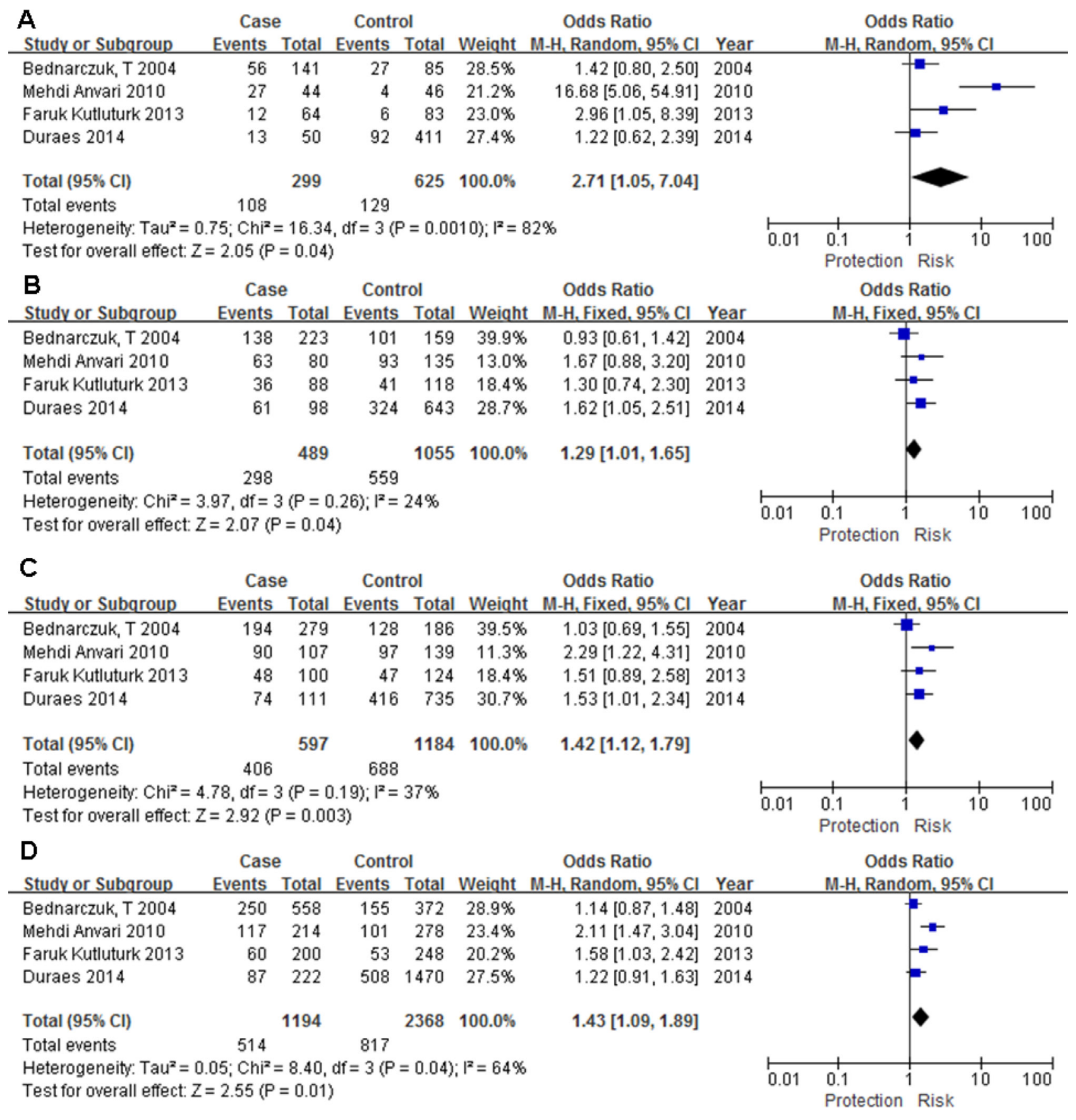

Figure 2: Forest plot for the association between IL-6 rs1800795 polymorphism and Graves' disease. (A) homozygous model (CC vs. GG), (B) heterozygous model (CG vs. GG), (C) dominant model (CC+CG vs. GG), (D) additive model (C vs. G). 
the IL6 rs1800795 polymorphism is functional and may be related to the pathogenesis of GD.

Except for IL-6, six variations in these genes (IL4 rs2243250, IL-4 rs2070874, IL-10 rs1800872, IL-12 rs3212227, $I L-13$ rs1800925, and $I L-13$ rs20541) did not show significant associations with GD in our metaanalysis. IL-10 is a major anti-inflammatory cytokine that is secreted by activated T cells, B cells, monocytes, and thymocytes [32]. IL-10 rs1800872 showed no association with GD in all of the tested population and had no heterogeneity. Thus, it is not likely to be a genetic marker for GD. Another five insignificant SNPs (IL-4 rs2243250, IL-4 rs2070874, IL-12 rs3212227, IL13 rs1800925, and $I L-13$ rs20541) also did not show an association with GD in all of the tested population with mild to high heterogeneities. IL-4 is a member of Th2 cytokines with anti-inflammatory properties, which reduces the production of proinflammatory cytokines and destructive enzymes by monocytes. Interestingly, we found that there were inconsistent conclusions even within the same ethnic group. For example Nanba and colleagues showed that rs2243250 in $I L-4$ was significantly associated with GD in the Japanese
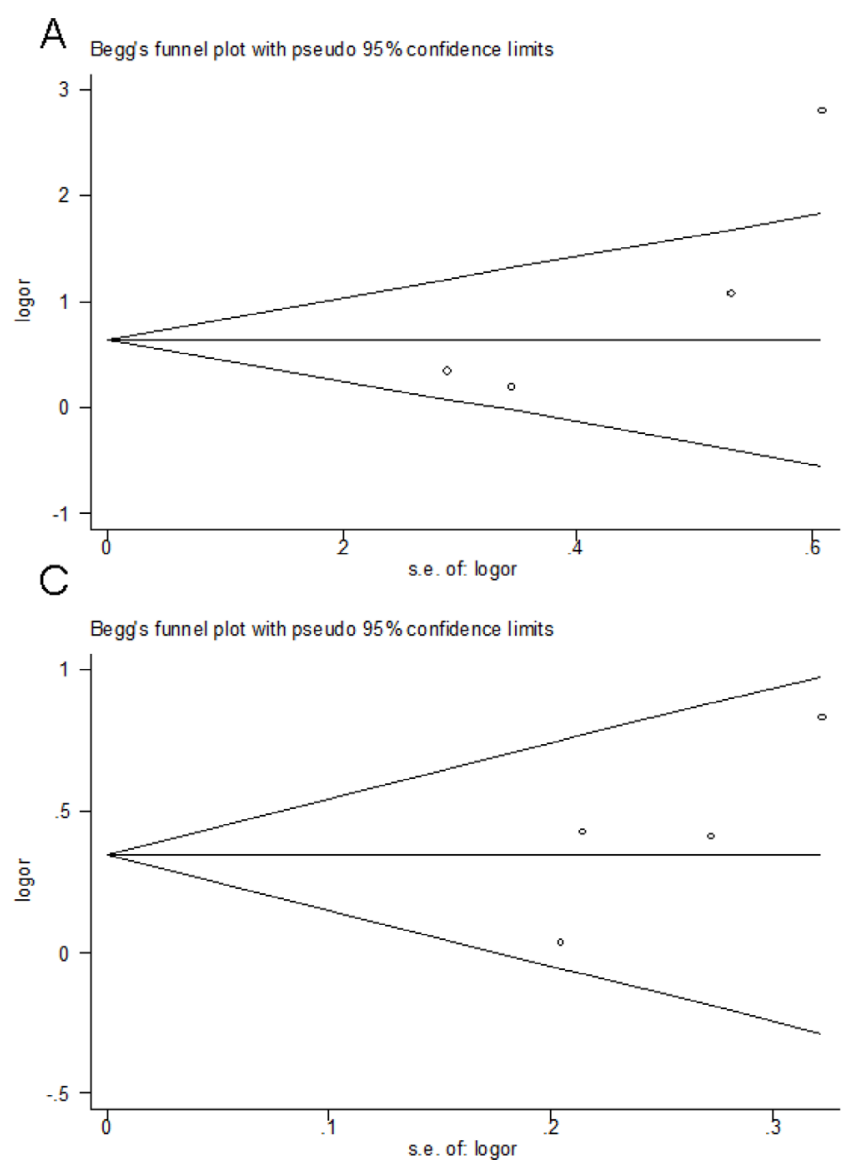

population [16], whereas Lee and colleagues failed to detect an association between $I L-4$ polymorphisms (rs2243250) and GD risk in a Chinese dataset [13]. This discrepancy is likely due to the differences in their lifestyle and diet, social and emotional stress, as well as their medical care and economic conditions. Of course, other factors such as study design and limited sample size, may also contribute to such discrepancies. Given that the associations between these genes and GD are still controversial, further replication studies of $I L-4$ gene among different population are warranted. IL-13 is an important immunoregulatory protein produced primarily by activated Th2 cells and is involved in B cell maturation. High serum IL-13 levels have been observed in patients with GD, which decrease significantly after treatment, suggesting that IL-13 gene polymorphisms are contributing to the development and severity of GD. However, we did not detect association of IL-13 with GD in our meta-analysis. This may be due to the limited number of included studies. IL-12 is an important cytokine that regulates innate resistance and adaptive immunity [33-34]. It has been demonstrated that the imbalance between Th1 and Th 2 cytokine production is
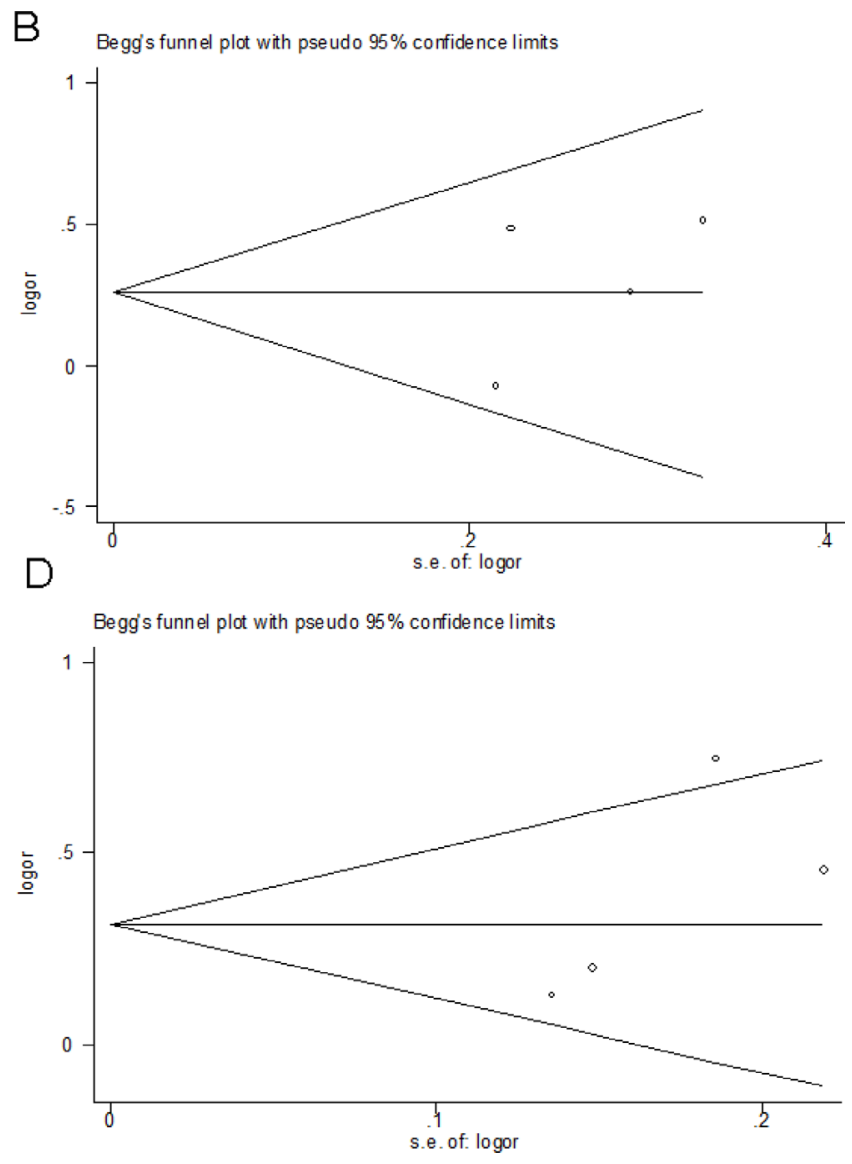

Figure 3: Funnel plot analysis to detect publication bias (SNP rs1800795 in $\boldsymbol{I L}$-6). Each point represents a separate study for the indicated association. (A) homozygous model (CC vs. GG), (B) heterozygous model (CG vs. GG), (C) dominant model (CC+CG vs. GG), (D) additive model (C vs. G). 
Table 3: Results for meta-analysis of polymorphism within Interleukin related genes with Graves' disease risk

\begin{tabular}{|c|c|c|c|c|c|c|c|c|c|c|}
\hline \multirow{2}{*}{ Gene } & \multirow{2}{*}{ Polymorphism } & \multirow{2}{*}{ No. of datasets } & \multirow{2}{*}{ Ethnicity } & \multirow{2}{*}{\multicolumn{2}{|c|}{$\begin{array}{c}\text { Genetic } \\
\text { model }\end{array}$}} & \multirow{2}{*}{ OR(95\% CI) } & \multirow{2}{*}{$p$ value } & \multicolumn{2}{|c|}{ Test of heterogeneity } & \multirow{2}{*}{$\begin{array}{c}p \text { for } \\
\text { publication } \\
\text { bias }^{\mathrm{a}}\end{array}$} \\
\hline & & & & & & & & $\mathbf{I}^{2}$ & $p$ value & \\
\hline \multirow[t]{5}{*}{ IL-4 } & \multirow[t]{5}{*}{ rs 2243250} & \multirow[t]{5}{*}{8} & \multirow{5}{*}{$\begin{array}{l}\text { Asian, } \\
\text { European }\end{array}$} & \multicolumn{2}{|l|}{ CC vs. TT } & $1.225(0.777,1.931)$ & 0.382 & $0 \%$ & 0.86 & 0.308 \\
\hline & & & & \multicolumn{2}{|l|}{ CT vs. TT } & $0.959(0.776,1.184)$ & 0.695 & $21.8 \%$ & 0.256 & 0.629 \\
\hline & & & & $\begin{array}{l}\mathrm{CC}+\mathrm{CT} \\
\mathrm{TT}\end{array}$ & vs. & $0.988(0.806,1.211)$ & 0.905 & $0 \%$ & 0.431 & 0.872 \\
\hline & & & & $\begin{array}{l}\mathrm{CC} \\
\mathrm{CT}+\mathrm{TT}\end{array}$ & vs. & $1.800(0.814,3.981)$ & 0.147 & $85.2 \%$ & 0.000 & 0.378 \\
\hline & & & & C vs. T & & $1.188(0.906,1.557)$ & 0.213 & $69.8 \%$ & 0.002 & 0.392 \\
\hline \multirow[t]{5}{*}{ IL-4 } & \multirow[t]{5}{*}{ rs2070874 } & \multirow[t]{5}{*}{3} & \multirow{5}{*}{$\begin{array}{l}\text { Asian, } \\
\text { European }\end{array}$} & \multicolumn{2}{|l|}{ CC vs. TT } & $0.261(0.02,3.366)$ & 0.303 & $86.2 \%$ & 0.001 & 0.451 \\
\hline & & & & \multicolumn{2}{|l|}{ CT vs. TT } & $0.273(0.022,3.4710$ & 0.317 & $85.7 \%$ & 0.001 & 0.386 \\
\hline & & & & $\begin{array}{l}\mathrm{CC}+\mathrm{CT} \\
\mathrm{TT}\end{array}$ & vs. & $0.269(0.02,3.551)$ & 0.319 & $86.6 \%$ & 0.001 & 0.430 \\
\hline & & & & $\begin{array}{l}\mathrm{CC} \\
\mathrm{CT}+\mathrm{TT}\end{array}$ & vs. & $0.871(0.526,1.27)$ & 0.369 & $68.0 \%$ & 0.044 & 0.810 \\
\hline & & & & C vs. T & & $0.747(0.416,1.342)$ & 0.330 & $88.8 \%$ & 0.000 & 0.763 \\
\hline \multirow[t]{5}{*}{ IL-6 } & \multirow[t]{5}{*}{ rs 1800795} & \multirow[t]{5}{*}{4} & \multirow{5}{*}{$\begin{array}{l}\text { Asian, } \\
\text { European }\end{array}$} & CC vs. GG & & $2.714(1.047,7.039)$ & 0.04 & $81.6 \%$ & 0.01 & 0.117 \\
\hline & & & & CG vs. GG & & $1.295(1.013,1.655)$ & 0.039 & $24.4 \%$ & 0.265 & 0.541 \\
\hline & & & & $\begin{array}{l}\mathrm{CC}+\mathrm{CG} \\
\mathrm{GG}\end{array}$ & vs. & $1.418(1.122,1.793)$ & 0.003 & $37.2 \%$ & 0.189 & 0.178 \\
\hline & & & & $\begin{array}{l}\mathrm{CC} \\
\mathrm{CG}+\mathrm{GG}\end{array}$ & vs. & $2.305(0.947,5.613)$ & 0.066 & $82.1 \%$ & 0.001 & 0.221 \\
\hline & & & & C vs. G & & $1.432(1.087,1.886)$ & 0.011 & $64.3 \%$ & 0.038 & 0.228 \\
\hline IL-10 & rs 1800872 & 3 & & AA vs. CC & & $1.123(0.86,1.467)$ & 0.394 & $48.1 \%$ & 0.146 & 0.388 \\
\hline & & & & $\mathrm{AC}$ vs. $\mathrm{CC}$ & & $1.127(0.942,1.35)$ & 0.191 & $40 \%$ & 0.366 & 0.299 \\
\hline & & & $\begin{array}{l}\text { Asian, } \\
\text { European }\end{array}$ & $\begin{array}{l}\mathrm{AA}+\mathrm{AC} \\
\mathrm{CC}\end{array}$ & vs. & $1.135(0.955,1.348)$ & 0.15 & $36.3 \%$ & 0.208 & 0.280 \\
\hline & & & & $\begin{array}{l}\mathrm{AA} \\
\mathrm{AC}+\mathrm{CC}\end{array}$ & vs. & $1.028(0.86,1.23)$ & 0.761 & $10.8 \%$ & 0.326 & 0.816 \\
\hline & & & & A vs. C & & $1.065(0.953,1.19)$ & 0.265 & $53.3 \%$ & 0.117 & 0.276 \\
\hline IL-12 & rs 3212227 & 3 & & CC vs. AA & & $0.634(0.206,1.949)$ & 0.427 & $86.7 \%$ & 0.001 & 0.2114 \\
\hline & & & & CA vs. AA & & $0.677(0.384,1.193)$ & 0.177 & $59.8 \%$ & 0.083 & 0.039 \\
\hline & & & Asian & $\begin{array}{l}\mathrm{CC}+\mathrm{CA} \\
\mathrm{AA}\end{array}$ & vs. & $0.636(0.3,1.348)$ & 0.237 & $79.3 \%$ & 0.008 & 0.095 \\
\hline & & & & CC vs. CA & $+\mathrm{A}$ & $0.883(0.417,1.869)$ & 0.744 & $83.7 \%$ & 0.002 & 0.729 \\
\hline & & & & C vs. A & & $0.804(0.473,1.367)$ & 0.421 & $87.0 \%$ & 0.000 & 0.388 \\
\hline IL-13 & rs 1800925 & 5 & & TT vs. CC & & $1.056(0.652,1.712)$ & 0.824 & $38 \%$ & 0.164 & 0.595 \\
\hline & & & & TC vs. CC & & $1.018(0.616,1.68)$ & 0.946 & $0 \%$ & 0.489 & 0.471 \\
\hline & & & $\begin{array}{l}\text { Asian, } \\
\text { European }\end{array}$ & $\begin{array}{l}\mathrm{TT}+\mathrm{TC} \\
\mathrm{CC}\end{array}$ & vs. & $1.055(0.656,1694)$ & 0.826 & $23.8 \%$ & 0.263 & 0.556 \\
\hline & & & & $\begin{array}{l}\text { TT } \\
\text { TC }+ \text { CC }\end{array}$ & vs. & $1.009(0.712,1.429)$ & 0.961 & $61.1 \%$ & 0.036 & 0.363 \\
\hline & & & & T vs. C & & $1.005(0.739,1.367)$ & 0.974 & $63.9 \%$ & 0.026 & 0.438 \\
\hline IL-13 & rs 20541 & 3 & & AA vs. GG & & $1.014(0.44,2.337)$ & 0.973 & $75.9 \%$ & 0.016 & 0.467 \\
\hline & & & & AG vs. GG & & $0.991(0.504,1.949)$ & 0.978 & $62.7 \%$ & 0.068 & 0.406 \\
\hline & & & $\begin{array}{l}\text { Asian, } \\
\text { European }\end{array}$ & $\begin{array}{l}\mathrm{AA}+\mathrm{AG} \\
\mathrm{GG}\end{array}$ & vs. & $1.006(0.473,2.14)$ & 0.987 & $72.9 \%$ & 0.025 & 0.499 \\
\hline & & & & $\begin{array}{l}\mathrm{AA} \\
\mathrm{AG}+\mathrm{GG}\end{array}$ & vs. & $1.083(0.869,1.35)$ & 0.476 & $39.7 \%$ & 0.19 & 0.005 \\
\hline & & & & A vs. G & & $1.036(0.756,1.418)$ & 0.828 & $70 \%$ & 0.036 & 0.146 \\
\hline
\end{tabular}

${ }^{a}$ :Egger's test was performed to assess publication bias. 
highly correlated with the induction and development of several autoimmune diseases including GD. Although rs3212227 in $I L-12$ are not significant in our metaanalysis, another SNP in IL-12 (rs568408) had show significant association with GD [35]. For this reason, the contributing role of the genetic variants of IL-12 needs further conformation in specific population.

Our meta-analysis has some key advantages. First, although other authors published such metaanalysis, they only studied the association between one of the interleukin genes and GD. However, our metaanalysis evaluated the "functional synergies" of Th1 (IL-12) and Th2 (IL-4, IL-6, IL-10 and IL-13) cytokines in autoimmune inflammation in the GD. Second, to guarantee the quality of this study, we included the most updated literature and used explicit criteria for study inclusion and a strict procedure for data extraction. Third, a substantial number of subjects were pooled from individual studies, which significantly increased the statistical power. However, there are several limitations in our study. First, the controls were hospital-based study in our included literatures. Compared with hospital-based study, a population-based case-control study can reduce more selection bias and have higher confidence. Second, our search was restricted to English-language studies. Some potential studies which were published in other languages or unpublished have been systematically excluded. This may explain some publication bias in our meta-analysis, which may have affected the results of this meta-analysis in as far as those studies that had produced negative results might not have been published. Third, the small number of published studies may lead to erroneous conclusions, especially among different ethnic group. What's more, since we were not able to obtain the original data, our further evaluation of geneto-environment interactions was limited.

In summary, the results of our meta-analysis identified that only rs1800795 within the $I L-6$ gene is associated with increased risk for developing GD. Owing to the limited number of included studies, future studies with a large dataset focusing on address their functional relevance would be necessary for fully establishing their effect on GD susceptibility.

\section{MATERIALS AND METHODS}

\section{Eligible studies}

PubMed, EMBASE and ISI Web of Science were searched (the last search was conducted on March 1, 2017) using the following search terms: "ILs" or "interleukins" and "Graves' disease" and "polymorphism". Reference, which were listed in each identified article, were also searched manually to identify additional eligible studies.

\section{Validity assessment}

To be eligible, the following inclusion criteria were established: (1) a human case-control study of a polymorphism associated with Graves' disease; (2) studies that included sufficient genotype data for extraction. Main exclusion criteria of studies were as follows: (1) case reports, letters, reviews, and editorial articles; (2) literature not containing information regarding diabetes research; (3) study involving only a case population; and (4) study not written in English. In the case of multiple studies by the same researchers involving the same or overlapping data sets, we selected the most recent study with the largest number of participants.

\section{Data extraction and quality assessment}

Two curators (Yaqin Tu and Guorun Fan) independently extracted information from included studies. Disagreement was resolved by discussion between the two authors. The following data were extracted: first author's name, year of publication, the ethnicities of the individuals involved, the genotyping method, number of cases and controls for each genotype, and the HardyWeinberg equilibrium (HWE) among the controls. Ethnicity was categorized as East Asian and European. A double-check procedure was performed to ensure accuracy of data entry. To evaluate the quality of included studies, we adopted the Newcastle-Ottawa Scale (NOS) with a nine-star system; this scale assesses the quality of cohort and case-control studies. NOS focuses on three separate sections of stars represents the assessment score. The maximal score of NOS is 9 stars: 4 stars for the selection process, 2 stars for comparability, and 3 stars for exposure/ outcome. A score of seven and above was represents the high-quality of study.

\section{Statistical analysis}

The strength of associations between IL-related genes and Graves' disease risk was measured by ORs with 95\% CIs. We explored the association between ILrelated genes and Graves' disease in homozygote (XX vs. $\mathrm{Xx}$ ), heterozygote (Xx vs. $\mathrm{Xx})$, dominant $(\mathrm{Xx}+\mathrm{XX}$ vs. $\mathrm{Xx}$ ), recessive ( $\mathrm{XX}$ vs. $\mathrm{Xx}+\mathrm{Xx}$ ), and additive ( $\mathrm{X}$ vs. $\mathrm{x}$ ) models respectively. Hardy-Weinberg equilibrium (HWE) was evaluated by the goodness-of-fit $\chi 2$ test for genotypes in the control group. Chi-squared-based $Q$-statistic test was employed to assess the between-study heterogeneity, and in any case $p<0.10$ was considered with significant heterogeneity between datasets. Once the effects were assumed to be homogenous, fixed-effects model was then applied (the Mantel-Haenszel method); otherwise, the random-effects model (DerSimonian and Laird method) was employed appropriately. Sensitivity analysis was 
performed to assess the influence of each individual study by omitting 1 study at a time and calculating a pooled estimate for the remainder of the studies. The inverted funnel plots and Egger's regression test were used to investigate publication bias. Potential publication bias was assessed with funnel plots of the effect sizes versus the standard errors; Begg's test was used to identify significant asymmetry. If there is evidence of publication bias, funnel plot is noticeably asymmetric. Concerning the significance level of the Begg's and Egger's tests was set at 0.05. All statistical tests carried out in the present report were two tailed. All analyses were conducted using the Review Manager 5.0.23 (Cochrane Library Software, Oxford, UK) and STATA 11.0 software (STATA Corporation, College Station, TX, USA).

\section{Abbreviations}

GD: Graves' disease; IL: Interleukin; Th1: T helper 1; TSH: thyroid-stimulating hormone; GWAS: genome-wide association studies; NOS: Newcastle-Ottawa Scale; CI: confidence interval; OR: odds ratio; SNPs: single nucleotide polymorphisms; HWE: Hardy-Weinberg equilibrium;

\section{Author contributions}

Conceived and designed the study strategy: W.K., X.C; Acquisition of data: statistical analysis and interpretation of data Y.Q.T., G.R.F.; Drafting or revision of the manuscript: Y.Q.T., G.R.F.; Reference collection and data management: T.S.Z.; Wrote the manuscript: Y.Q.T.; Prepared the tables and figures: G.R.F.; Study supervision: W.K., X.C; All authors reviewed the manuscript.

\section{ACKNOWLEDGMENTS}

Thanks to Dr. Mohmmad Ishraq Zafar for polishing our manuscript. This work was supported by the National Natural Science Foundation of China (81500796 and 81500620).

\section{CONFLICTS OF INTEREST} interest

The authors declare that they have no conflicts of

\section{REFERENCES}

1. Smith TJ, Hegedus L. Graves' Disease. N Engl J Med. 2016; 375:1552-1565.

2. McLeod DS, Cooper DS. The incidence and prevalence of thyroid autoimmunity. Endocrine. 2012; 42:252-265.

3. Brix TH, Kyvik KO, Christensen K, Hegedus L. Evidence for a major role of heredity in Graves' disease: a populationbased study of two Danish twin cohorts. J Clin Endocrinol Metab. 2001; 86:930-934.
4. Brix TH, Kyvik KO, Hegedus L. A population-based study of chronic autoimmune hypothyroidism in Danish twins. J Clin Endocrinol Metab. 2000; 85:536-539.

5. Akamizu T, Hiratani H, Ikegami S, Rich SS, Bowden DW. Association study of autoimmune thyroid disease at 5q23-q33 in Japanese patients. J Hum Genet. 2003; 48:236-242.

6. Khalilzadeh O, Anvari M, Momen-Heravi F, Esteghamati A, Rashidi A, Mahmoudi M, Nikbin B, Amirzargar A. Gene polymorphisms of interleukin-4, interleukin-10 and transforming growth factor-beta in Graves' disease. Clin Exp Med. 2010; 10:123-128.

7. Liu N, Lu H, Tao F, Guo T, Liu C, Cui B, Ning G. An association of interleukin-10 gene polymorphisms with Graves' disease in two Chinese populations. Endocrine. 2011; 40:90-94.

8. Tian G, Li JL, Wang DG, Zhou D. Targeting IL-10 in autoimmune diseases. Cell Biochem Biophys. 2014; 70:37-49.

9. Zhu W, Liu N, Zhao Y, Jia H, Cui B, Ning G. Association analysis of polymorphisms in IL-3, IL-4, IL-5, IL-9, and IL-13 with Graves' disease. J Endocrinol Invest. 2010; 33:751-755.

10. Komiya I, Yamada T, Sato A, Kouki T, Nishimori T, Takasu N. Remission and recurrence of hyperthyroid Graves' disease during and after methimazole treatment when assessed by IgE and interleukin 13. J Clin Endocrinol Metab. 2001; 86:3540-3544.

11. Jang JP, Cho WK, Baek IC, Choi EJ, Shin DH, Suh BK, Kim TG. Comprehensive analysis of cytokine gene polymorphisms defines the association of IL-12 gene with ophthalmopthy in Korean children with autoimmune thyroid disease. Mol Cell Endocrinol. 2016; 426:43-49.

12. Inoue $N$, Watanabe M, Morita M, Tatusmi K, Hidaka Y, Akamizu T, Iwatani Y. Association of functional polymorphisms in promoter regions of IL5, IL6 and IL13 genes with development and prognosis of autoimmune thyroid diseases. Clin Exp Immunol. 2011; 163:318-323.

13. Lee YJ, Huang CY, Ting WH, Lee HC, Guo WL, Chen WF, Lin CL, Liu HF, Lin M, Lo FS. Association of an IL-4 gene haplotype with Graves disease in children: experimental study and meta-analysis. Hum Immunol. 2011; 72:256-261.

14. Anvari M, Khalilzadeh O, Esteghamati A, Momen-Heravi F, Mahmoudi M, Esfahani SA, Rashidi A, Amirzargar A. Graves' disease and gene polymorphism of TNF-alpha, IL-2, IL-6, IL-12, and IFN-gamma. Endocrine. 2010; 37:344-348.

15. Chong KK, Chiang SW, Wong GW, Tam PO, Ng TK, $\mathrm{Hu}$ YJ, Yam GH, Lam DS, Pang CP. Association of CTLA4 and IL-13 gene polymorphisms with Graves' disease and ophthalmopathy in Chinese children. Invest Ophthalmol Vis Sci. 2008; 49:2409-2415.

16. Nanba T, Watanabe M, Akamizu T, Iwatani Y. The -590CC genotype in the IL4 gene as a strong predictive factor for the development of hypothyroidism in Hashimoto disease. Clin Chem. 2008; 54:621-623.

17. Chen RH, Chang CT, Wang TY, Chen CC, Tsai CH, Tsai FJ. Lack of association between interleukin-4 gene 
polymorphisms and autoimmune thyroid diseases amongst Taiwanese Chinese. Endocrine. 2007; 32:170-174.

18. Shiau MY, Huang CN, Yang TP, Hwang YC, Tsai KJ, Chi CJ, Chang YH. Cytokine promoter polymorphisms in Taiwanese patients with Graves' disease. Clin Biochem. 2007; 40:213-217.

19. Hiromatsu Y, Fukutani T, Ichimura M, Mukai T, Kaku H, Miyake I, Yamada K. Interleukin-12B gene polymorphism does not confer susceptibility to Graves' ophthalmopathy in Japanese population. Endocr J. 2006; 53:753-759.

20. Yang Y, Lingling S, Ying J, Yushu L, Zhongyan S, Wei H, Weiping T. Association study between the IL4, IL13, IRF1 and UGRP1 genes in chromosomal 5q31 region and Chinese Graves' disease. J Hum Genet. 2005; 50:574-582.

21. Ikeda Y, Yoshida W, Noguchi T, Asaba K, Nishioka T, Takao T, Hashimoto K. Lack of association between IL12B gene polymorphism and autoimmune thyroid disease in Japanese patients. Endocr J. 2004; 51:609-613.

22. Bednarczuk T, Kurylowicz A, Hiromatsu Y, Kiljanskic J, Telichowska A, Nauman J. Association of G-174C polymorphism of the interleukin-6 gene promoter with Graves' ophthalmopathy. Autoimmunity. 2004; 37:223-226.

23. Hiromatsu Y, Fukutani T, Ichimura M, Mukai T, Kaku H, Nakayama H, Miyake I, Shoji S, Koda Y, Bednarczuk T. Interleukin-13 gene polymorphisms confer the susceptibility of Japanese populations to Graves' disease. J Clin Endocrinol Metab. 2005; 90:296-301.

24. Hunt PJ, Marshall SE, Weetman AP, Bell J, Wass JA, Welsh KI. Cytokine gene polymorphisms in autoimmune thyroid disease. J Clin Endocrinol Metab. 2000; 85:1984-1988.

25. Duraes C, Moreira CS, Alvelos I, Mendes A, Santos LR, Machado JC, Melo M, Esteves C, Neves C, SobrinhoSimoes M, Soares P. Polymorphisms in the TNFA and IL6 genes represent risk factors for autoimmune thyroid disease. PLoS One. 2014; 9:e105492.

26. Kutluturk F, Yarman S, Sarvan FO, Kekik C. Association of cytokine gene polymorphisms (IL6, IL10, TNF-alpha, TGF-beta and IFN-gamma) and Graves' disease in Turkish population. Endocr Metab Immune Disord Drug Targets. $2013 ; 13: 163-167$.
27. Tait KF, Nithiyananthan R, Heward JM, Barnett AH, Franklyn JA, Gough SC. Polymorphisms of interleukin 4 receptor gene and interleukin 10 gene are not associated with Graves' disease in the UK. Autoimmunity. 2004; 37:189-194.

28. Bednarczuk T, Placha G, Jazdzewski K, Kurylowicz A, Kloza M, Makowska U, Hiromatsu Y, Nauman J. Interleukin-13 gene polymorphisms in patients with Graves' disease. Clin Endocrinol (Oxf). 2003; 59:519-525.

29. Heward JM, Nithiyananthan R, Allahabadia A, Gibson S, Franklyn JA, Gough SC. No association of an interleukin 4 gene promoter polymorphism with Graves' disease in the United Kingdom. J Clin Endocrinol Metab. 2001; 86:3861-3863.

30. Barbieri M, Rizzo MR, Papa M, Acampora R, De Angelis L, Olivieri F, Marchegiani F, Franceschi C, Paolisso G. Role of interaction between variants in the PPARG and interleukin- 6 genes on obesity related metabolic risk factors. Exp Gerontol. 2005; 40:599-604.

31. Berkovic MC, Jokic M, Marout J, Radosevic S, ZjacicRotkvic V, Kapitanovic S. IL-6-174 C/G polymorphism in the gastroenteropancreatic neuroendocrine tumors (GEPNETs). Exp Mol Pathol. 2007; 83:474-479.

32. Couper KN, Blount DG, Riley EM. IL-10: the master regulator of immunity to infection. J Immunol. 2008; 180:5771-5777.

33. Trinchieri G. Interleukin-12: a proinflammatory cytokine with immunoregulatory functions that bridge innate resistance and antigen-specific adaptive immunity. Annu Rev Immunol. 1995; 13:251-276.

34. Trinchieri G. Interleukin-12 and the regulation of innate resistance and adaptive immunity. Nat Rev Immunol. 2003; 3:133-146.

35. Guo T, Yang S, Liu N, Wang S, Cui B, Ning G. Association study of interleukin-12A gene polymorphisms with Graves' disease in two Chinese populations. Clin Endocrinol (Oxf). 2011; 74:125-129. 